\title{
A Study of Impact of Cloud Computing and Artificial Intelligence on Banking Services, Profitability and Operational Benefits
}

\author{
Sadhana Tiwari ${ }^{1}$, Shashank Bharadwaj ${ }^{2}$,Dr. Sunil Joshi \\ Assistant Professor ${ }^{1}$, School of Business Studies, Sharda University \\ Assistant Professor ${ }^{2}$, School of Business Studies, Sharda University \\ Professor ${ }^{3}$, School of Business Studies, Sharda University
}

Article History: Received: 10 November 2020; Revised 12 January 2021 Accepted: 27 January 2021; Published online: 5 April 2021

\begin{abstract}
Banks have seen a convergence in end-customer banking interactions over the last decade, owing to IT-enabled solutions and services such as Core Banking, Online Banking, Mobile Banking, Wallet, Wallets Kiosk Banking. The evolution of IT in the banking industry supports both banks and their clients. Banks' business models are now centered on delivering consumer joy via IT-enabled solutions and services. Cloud technology allows banks to follow a digital paradigm for providing novel channels, reducing TAT to market new offerings, fulfilling consumer expectations, and adhering to regulatory requirements at a lower cost. In constantly evolving technical paradigms, cloud-based solutions offer a higher value proposition to IT solutions and services. Device administrators can remotely assemble, upload, customize, and execute virtual tools to manage a business solution using cloud infrastructure. Furthermore, cloud IT technology can be scaled up or down at any time based on planned use and specifications without incurring high costs. To assess the impact of cloud computing and artificial intelligence in operational and service advantage Confirmatory factor analysis (CFA) technique is used. The thesis demonstrates how well the measured variables reflect the number of constructs and whether the estimation hypothesis is confirmed or rejected.
\end{abstract}

Keywords: Confirmatory Factor Analysis (CFA), Cloud Computing, Artificial Intelligence, Banking,

\section{Introduction}

Because of the importance of the banking market, banking has historically been a conservative sector for adopting newer technology. Furthermore, since banks work with public funds, they are subject to tight supervision and governance. Despite their cautious stance and regulatory stresses, current market uncertainty pushes banking and financial institutions (FIs) to search for ways to cut operating expenses and introduce new products that can offer greater market penetration and a faster return on investment. Banks' IT technology accounts for a large portion of their running expenses.

To provide a robust and cost-effective IT approach, banks should consider cloud computing. When cloud storage was first adopted, cloud maturity levels were limited. Banks and financial institutions were hesitant to accept it because they are bound by rules, data protection, and 
regulations. The cloud room has evolved considerably, and most banking standards and legislation have been updated to accommodate cloud storage, flooring the way for banks to implement cloud services.

Furthermore, over a working day, the workload in a banking system varies greatly. Previously, most financial infrastructure was made up of a Core Banking Solution (CBS) and multi-channel channels. Progressive analytics, real-time marketing monitoring, and client service analytics, which are compute-intensive, are all part of the infrastructure. This illustrates the need for a business case for banking CIOs and CTOs to explore cost-effective platforms, such as cloud storage.

In India's banking and financial markets space, cloud platforms have gained some momentum and acceptance recently; however, the degree of adoption varies depending on the appetite for operating cost savings and openness to adopting newer technology. A host of analyst reports, including Gartner's 1, rapid forecast growth in India's public cloud services sector (the most recent Gartner study suggested an increase at 33 percent in 2015). As some Indian banks have shown, the advantages of cloud computing adoption are considerable, but the industry must be prepared for related challenges.

The advantages of cloud computing adoption, as well as deployable architectures, are well articulated and demonstrated. Cloud storage comes with its security and enforcement issues that must be adequately understood before getting started. Simultaneously, cloud computing holds the ability to improve security policies and enhance protections. This White Paper includes information to help manage different banking institutions embrace and implement cloud infrastructure while still exercising effective governance and oversight to achieve good business benefits while minimizing risk.

The banking sector houses a considerable amount of customer data and is constantly aiming to offer its clients the best services. In such a case, cloud storage technology acts as a revolutionary digital approach that provides the banking sector with unprecedented security, mobility, and scalability while enhancing its ability to manage customer data.

Strategically deployed cloud computing systems allow banks to use capital in a highly flexible and efficient manner through data analytics, data storage, and batch processing. In addition, cloud technology helps the banking industry progress revenue, operational performance, and customer service. The cloud enables the banking sector to rapidly adapt to changing consumer and business demands. It provides banks with more room to meet future consumer demands, allowing them to remain afloat in the industry.

The banking industry's growth, mobility, and quality will all benefit from cloud-based services. It will assist banks in reallocating capital and relieving their IT infrastructure management's IT workers, enabling them to concentrate on more innovative activities such as reducing the time to market for goods and services. On-demand cloud platforms allow the banking industry to scale infrastructure in response to customer demands dynamically. With the aid of cloud 
technologies, the power, redundancy, and resiliency risks associated with legacy technology can be easily reduced.

Cloud infrastructure allows banks to integrate emerging technologies and innovations as they become available in the future, increasing their activities' efficiency. It allows bank IT staff to focus on their core business practices and establish procedures for improved operational efficiency.. Cloud computing can also help banks remove complications associated with data transitions and growth by using unified data processing.

Cloud infrastructure enables banks to provide more competitive goods and services. It not only allows the banking industry to expand computing capability in order to meet rising market demands, but it also provides deeper perspectives, enabling banks to create more customized services for their clients. Although cloud computing has the potential to change the banking industry, it is essential to choose cloud computing services only from India's leading cloud service providers. They are internationally recognized accredited consultants with extensive expertise in providing banks with personalized, state-of-the-art cloud solutions that increase their overall business.

\section{Review of literature}

Business techniques and technologies were combined in the last decade of the twentieth century (Chester, 1994) to revamp the business model. The importance of technology investments in competitiveness and economic gains were measured (Brynjolfsson \& Hitt, 2000).

The human brain's ability to interpret information and solve problems has prompted scientists to try to imbue robots with equal knowledge (Shachmurove, 2002). Since banks play such a significant position in a country's economic development, their effective policy execution, using cutting-edge technology, brings importance not just to their sector but also to the country's economy and growth. As a result, banks must keep up with the growing demands of today's constantly evolving market (Brauer, 2005), aligning their strategies to fulfil those expectations (Alam \& Khokhar, 2006).

A system that can act like an individual, research languages, execute physical activities, and mimic human decision making (Russel \& Norvig, 2003) is created by uniting various methods of machine learning, pattern acknowledgment, logic, and probability theory, as well as biologically based models (Brachman, 2006). Since system and information features have a huge impact on user loyalty and trust, customers' trust in technology helped pave the means for mobile banking payments (Donner \& Tellez, 2008). (Lee \& Chung, 2009).

AI is now being used to evaluate bank results (Fethi \& Pasiouras, 2010). In fields of accounting, auditing, and assurance, through gathering, analyzing, and generating reliable financial results, information technology is extensively used by the banking industry around the world (Vedapradha, Ravi, \& Jebasingh, 2016), easing some of the most complex challenges and assisting decision-making. (Davenport, 2016). 
Banks are moving forward by designing Specialist Support Systems (ESS) and Decision Support Systems (DSS) to assist managers in making additional informed decisions and policies in critical ranges such as service quality (Castelli, Manzoni, \& Popovic, 2016), credit risk assessment, loan defaulters, efficient acquisitions, and interest rate inflation, among others (Ghodselahi \& Amir, 2016). 2016 (Vedapradha, Ravi, and Jebasingh).

Researchers have introduced an end-to-end Robotic Background with comprehensive hardware and algorithmic aspects that can be extended to a range of industries in response to the need for complex structures that can detect trends in consumer data and change financial tactics accordingly so that consumers can offer pragmatic and timely service (Nuseibeh, 2017). (Chakroborty, 2017).

The capacity of low-cost development, open-source system, and usability of the same are the key factors motivating AI into the banking sector; hence, over the next three years, without depending on bank branches or actual cheque books, AI is expected to become the main way banks transact with their customers (Sinha, 2017). To best serve its young tech-savvy clients, India's banking industry is investing in robotics and artificial intelligence (Ayachit, 2017). Banking goods have come a long way from India's conventional banking (KUMAR, 2018).

The use of emerging technology by banks in the execution of their initiatives to achieve productivity is commendable (Lagarde, 2018), and it is planned that with the aid of AI, they will be able to establish internationally coherent practices procedures, and frameworks (Erdélyi \& Goldsmith, 2018). AI has a strong positive relationship $(\mathrm{R}$ - coefficient $=0.859)$ with appropriate record possession (Longinus, 2018). By optimizing investment strategy, handling customers' records, performing risk analyses, preventing money laundering, and adding value by reducing money movement costs while growing efficiencies, AI has the ability to turn all banking operations (Ghurair, 2018). (Kurode, 2018).

Human bank workers are currently undertaking a vast number of unproductive, tedious jobs, while the human workforce for innovative and decision-making positions is limited (Kurode, 2018).

The preceding paragraph contains information on the technological, practical, and strategic facets of AI and its importance to market policy to assist banks in deciding whether or not to follow AI. Scholars have already completed a significant amount of work, and more is being added to the information repository every day. According to one report, AI adoption in the banking sector could improve India's economy by $\$ 1$ trillion by 2035 . (Lakshminarayana \& Deepthi, 2019).

The Reserve Bank of India has highly indorsed technology to apply laws and develop policy agendas in India's banking sector under the direction of Dr. Raghuram Rajan and Urjit Patel (Aazhvaar, 2019). Designing a strategy, on the other hand, is much superior to putting it into action. The same can be said for a nation like India, which has a huge population and a high 
proportion of rural or non-tech savvy people, thus slowing the introduction of technologyenabled services. (Kurode, 2018).

\section{Objectives of the Study}

I. To assess the impact of cloud computing and artificial intelligence in Efficient client service, Business Continuity and Improved operational efficiency and Business agility in the banking industry.

II. To assess the impact of cloud computing and artificial intelligence in Access to automatic updates, Auto scalability, green banking promotion and cost reduction.

III. To assess the impact of cloud computing and artificial intelligence in security enhancement and backup management.

\section{Hypotheses}

I. There is no impact of cloud commuting and artificial intelligence in Efficient client service, business continuity, and Improved operational efficiency and Business agility in the banking industry.

II. There is no impact of cloud computing and artificial intelligence in Access to automatic updates, Auto scalability, green banking promotion and cost reduction

III. There is no impact of cloud computing and artificial intelligence in security enhancement and backup management.

\section{Methodology}

The study was supported by a literature review, which tended to minimize challenges to scientific validity. To validate the relationship between the variables, Jamovi was used to conduct statistical analysis on the study queries, dependent and independent variables.

Fifteen banks, ten respondents each, in the bank branches have been selected and handed over a close-ended questionnaire for primary data collection, and numerical scaling technique was used, and responses were rated 1- 10. The two ends of the continuum represent the two extremes of the measuring phenomena. As far as cloud computing is concerned in these bank branches, primary respondents said that this whole industry runs on cloud computing. In our study, we selected few regional rural banks, where cloud computing is functional but not as aggressive as observed in urban areas.

The confirmatory factor analysis methodology was used to investigate causal relationships between latent and observable variables in a priori defined, theory-derived models. CFA's key benefit is that it will help researchers bridge the distance between hypothesis and observation, which is often encountered. An instrument, for example, maybe generated by making several objects for any of several theoretical constructs. CFA may provide helpful information to the investigator about the data's fit to a particular, theory-derived measuring model (where items load only on the variables they were intended to measure) and point out specific items' possible flaws. From model conceptualization, recognition, and parameter estimation to data-model fit evaluation and possible model adjustment, CFA is better interpreted as a method. In contrast to exploratory approaches, CFA's value is its disconformity: models or hypotheses may be 
discarded, but the findings can still lead to new changes that should be studied further in subsequent studies.

\section{Data Interpretation, Analysis \& Results}

Table 1

\begin{tabular}{|c|c|c|c|}
\hline Levels & Counts & $\%$ of Total & Cumulative \% \\
\hline 3 & 5 & $3.3 \%$ & $3.3 \%$ \\
\hline 4 & 5 & $3.3 \%$ & $6.7 \%$ \\
\hline 6 & 11 & $7.3 \%$ & $14.0 \%$ \\
\hline 7 & 6 & $4.0 \%$ & $18.0 \%$ \\
\hline 8 & 38 & $25.3 \%$ & $43.3 \%$ \\
\hline 9 & 54 & $36.0 \%$ & $79.3 \%$ \\
\hline 10 & 31 & $20.7 \%$ & $100.0 \%$ \\
\hline
\end{tabular}

\section{Interpretation}

Fifteen banks, ten respondents each, in the bank branches have been selected and handed over a close-ended questionnaire for primary data collection, and numerical scaling technique was used, and responses were rated 1- 10. The two ends of the continuum represent the two extremes of the measuring phenomena. As far as cloud computing is concerned in these bank branches, primary respondents said that this whole industry runs on cloud computing. Our study selected a few regional rural banks, where cloud computing is functional but not as aggressive as observed in urban areas.

Table 2: Confirmatory Factor Analysis

Factor Loadings

\begin{tabular}{|c|c|c|c|c|c|}
\hline Factor & Indicator & Estimate & SE & $\mathbf{Z}$ & $\mathbf{p}$ \\
\hline \multirow[t]{3}{*}{ Banking services } & Efficient client service & 1.38 & 0.0996 & 13.892 & $<.001$ \\
\hline & Business Continuity & 1.35 & 0.1158 & 11.691 & $<.001$ \\
\hline & $\begin{array}{l}\text { Improved operational efficiency and Business } \\
\text { agility }\end{array}$ & 5.37 & 2.7122 & 1.981 & 0.048 \\
\hline \multirow[t]{5}{*}{ Profitability } & Access to automatic updates & 1.76 & 0.1135 & 15.520 & $<.001$ \\
\hline & Auto scalability & 1.79 & 0.1180 & 15.136 & $<.001$ \\
\hline & $\begin{array}{l}\text { Improved operational efficiency and Business } \\
\text { agility }\end{array}$ & -3.60 & 2.7201 & -1.325 & 0.185 \\
\hline & green banking has been promoted & -4.39 & 6.1891 & -0.709 & 0.478 \\
\hline & cost reduction & 1.86 & 0.1174 & 15.880 & $<.001$ \\
\hline $\begin{array}{l}\text { Operational } \\
\text { benefits }\end{array}$ & Access to automatic updates. & 1.74 & 0.1151 & 15.109 & $<.001$ \\
\hline
\end{tabular}


Factor Loadings

\begin{tabular}{llcrrrr}
\hline \multirow{2}{*}{ Factor } & \multicolumn{1}{c}{ Indicator } & Estimate & $\mathbf{S E}$ & $\mathbf{Z}$ & $\mathbf{p}$ \\
\hline & green banking has been promoted & 6.10 & 6.1934 & 0.984 & 0.325 \\
& security enhanced & 1.72 & 0.1131 & 15.170 & $<.001$ \\
& backup management has become easier & 1.69 & 0.1075 & 15.690 & $<.001$ \\
\hline
\end{tabular}

\section{Interpretation}

Confirmatory factor analysis (CFA) is a multivariate statistical technique for determining whether calculated variables accurately reflect the number of constructs. Confirmatory factor analysis (CFA) is a technique for confirming or disproving estimation theories. The above-stated table observed that Efficient client service, Business Continuity, Access to automatic updates, Auto scalability, improved operational efficiency, cost reduction security enhanced, and backup management improvised significantly due to cloud computing and artificial intelligence. Operational efficiency and green banking were assumed to be significant advantages of banking, although their negative estimation was the opposite of the assumption. Hence this can be concluded as per the study result except, operational efficiency and green banking, all other measured variables confirm the measurement theory.

Table 3: Factor Estimates

Factor Covariances

\begin{tabular}{|c|c|c|c|c|c|}
\hline & & Estimate & SE & $\mathbf{Z}$ & $\mathbf{p}$ \\
\hline \multirow[t]{3}{*}{ Banking services } & Banking services & $1.000^{\mathrm{a}}$ & & & \\
\hline & Profitability & 0.964 & 0.02220 & 43.4 & $<.001$ \\
\hline & Operational benefits & 0.959 & 0.02483 & 38.6 & $<.001$ \\
\hline \multirow[t]{2}{*}{ Profitability } & Profitability & $1.000^{\mathrm{a}}$ & & & \\
\hline & Operational benefits & 0.998 & 0.00253 & 394.2 & $<.001$ \\
\hline Operational benefits & Operational benefits & $1.000^{\mathrm{a}}$ & & & \\
\hline
\end{tabular}

\section{Interpretation}

Factor estimates show that banking services and profitability have a high positive association as the estimated value of ( 0.964$)$ is close to +1 ; hence, if banking services are to be improvised, profitability and operational benefit both will improvise too. 
Table 4: Model Fit

Test for Exact Fit

\begin{tabular}{ccc}
\hline$\chi^{2}$ & df & $\mathbf{p}$ \\
\hline 161 & 30 & $<.001$ \\
\hline
\end{tabular}

Table 5: Fit Measures

\begin{tabular}{lllll}
\hline & & & & \multicolumn{2}{c}{ RMSEA 90\% CI } \\
\cline { 4 - 5 } CFI & TLI & RMSEA & Lower & Upper \\
\hline \multirow{2}{*}{0.946} & 0.919 & 0.170 & 0.145 & 0.197 \\
\hline
\end{tabular}

\section{Interpretation}

The disparity between observed and expected covariance matrices can be seen using the chisquared test. The difference between the expected and observable covariance matrices is smaller when the values are closer to zero. Chi-squared figures may also be used to assess how well nested models specifically complement the results. Because.001 is so close to zero, it means that the formula is more accurate.

The comparative fit index (CFI) evaluates model fit by comparing the results to the hypothesised model, which eliminates the sample size issues that plague the chi-squared test of model fit and the normed fit index. Higher numbers indicate a stronger fit on the CFI scale, which ranges from 0 to 1 . As a result of (0.946) being closer to 1 , it can be inferred that the index is model suited.

Figure 1: Validated Model of the impact of work culture dynamics

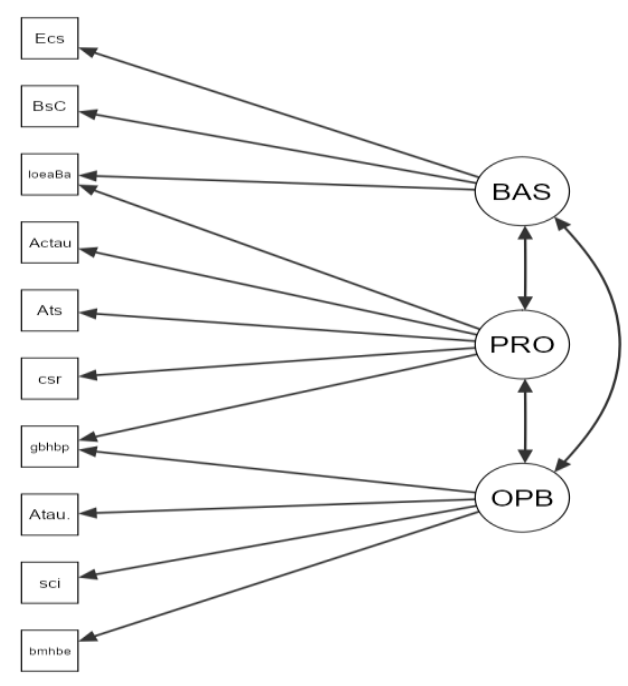


Though path analysis is useful for testing causal theories, it can't tell you which way the caus ality is going. It clarifies association and shows the frequency of a causal theory, but it does not demonstrate causation path. Researchers may perform laboratory experiments in which $\mathrm{p}$ atients are randomly assigned to a therapy or control group in order to best explain the path of causality. The data sets were combined, and a unified model was created to understand the impact of cloud computing on Efficient client service, Business Continuity, Access to automatic updates, Auto scalability, improved operational efficiency, cost reduction, security enhanced and backup management Using Partial Least Square, a structured equation model was created that is illustrated in figure 1 as above.

Figure 2: Estimated Model using PLS

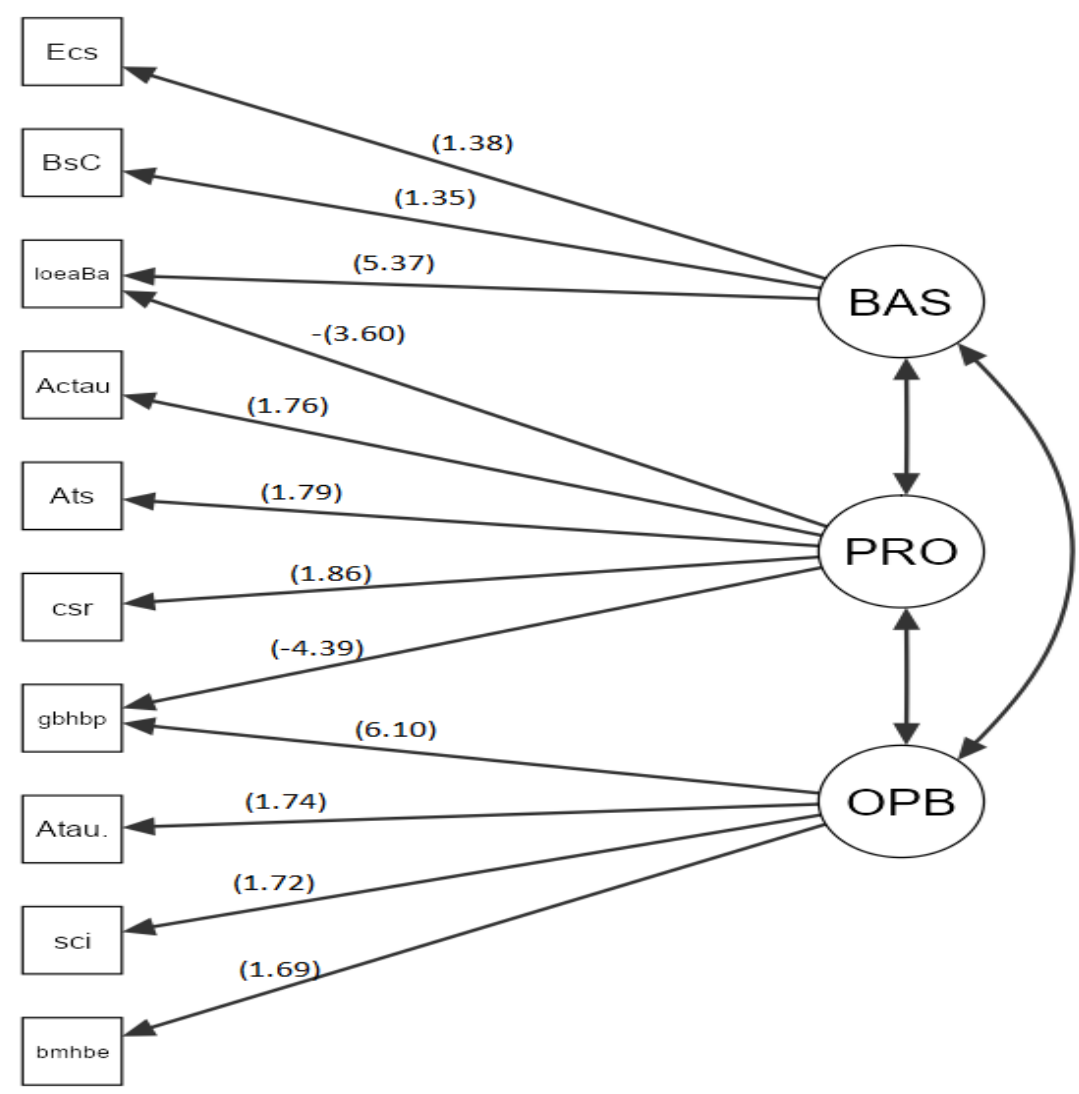

Cloud computing and artificial intelligence positively impact Efficient client service, Business Continuity, Access to automatic updates, Auto scalability, improved operational efficiency, cost reduction, security enhanced and backup management. operational efficiency and green banking negative estimation is opposite to general assumption.

\section{Conclusion}

banks will have to work together to address the complexities of cloud infrastructure in the banking industry if it is to continue to progress. Banks should select service and distribution models that better complement organizational stability, cost effectiveness, and pay-as-you-go models when planning cloud computing projects in the near future. Banks should take a stepby-step approach to cloud computing services, reviewing each initiative depending on the type 
of software and data involved. Customer experience management and enterprise content management are examples of low-risk programmes. Ventures requiring central business operating structures, such as wealth management or core banking, would be riskier. In the long run, banks will provide a combination of on-premise and cloud-based systems implemented through a variety of private, hybrid, and public cloud deployment models, with cloud providers increasing their share of the service mix. Private clouds are supposed to become a more prevalent way for banks to incorporate cloud technology, as they give them complete control of their cloud infrastructure, both in terms of ownership and function.

Financial institutions should select service and distribution models that better complement organizational stability, cost efficiency, and pay-as-you-use models when planning cloud infrastructure projects in the near future. Banks, according to Capgemini, should take a stepby-step approach to cloud computing resources, reviewing each project depending on the type of applications and the quality of the data. Customer experience management and enterprise content management are examples of low-risk programmes. Ventures requiring central business operating structures, such as wealth management or core banking, would be riskier. Capgemini anticipates that banks will eventually provide a combination of on-premise and cloud-based services through a variety of private, hybrid, and public cloud-based delivery models, with cloud services increasing their share of the service mix. Private clouds are predicted to become more prevalent in the coming years. implementation model for cloud services among banks, allowing them total control over their cloud systems by ownership and operations.

\section{References}

1. Alam, M., \& Khokhar, R. (2006). Impact of Internet on Customer Loyalty in Swedish Banks. J. Econ. Psychol. Apr 7;16:311-29.

2. Ardito, L., Petruzzelli, A. M., Panniello, U., \& Achille, C. (2019). Towards Industry 4.0. Business Process Management Journal, Bradford Vol. 25, Iss. 2, pp: 323-346.

3. Awad, R. (2011). Considerations on Cloud Computing for CPAs. The CPA Journal, New York Vol. 81, Iss. 9, Sep pp: 11-12.

4. Ayachit, M. M. (2017). ICT Innovation in Indian Banking Sector: Trends and Challenges. IOSR Journal of Business and Management (IOSR-JBM), PP 21-27.

5. Bellman, R. (1978). An Introduction to Artificial Intelligence: Can Computers Think? San Francisco: Boyd \& Fraser Pub. Co.

6. Bidgoli, H. (2018). Cloud Computing Deployment: What Have We Learned from Real Life Implementations and Practices. Journal of Strategic Innovation and Sustainability, West Palm Beach Vol. 13, Iss. 1, Jul pp 36- 52.

7. Castelli, M., Manzoni, L., \& Popovic, A. (2016). An Artificial Intelligence System to Predict Quality of Service in Banking Organizations. Computational Intelligence and Neuroscience, http://dx.doi.org/10.1155/2016/9139380.

8. Chakroborty, A. (2017). Futuristic Robotic Technology in Retail and Banking. Imperial Journal of Interdisciplinary Research (IJIR), ISSN: 2454-1362, Vol-3, Issue-3, 291 - 299.

9. Donner, J., \& Tellez, C. A. (2008). Mobile banking and economic development:linking adoption, impact, and use. Asian Journal of Communication, 18(4), 318-332.

10. Fethi, M., \& Pasiouras, F. (2010). Assessing Bank Efficiency and Performance with Operational Research and Artificial Intelligence Techniques: A Survey. European Journal of Operational Research, Vol. 204 (2). pp. 189- 198. 
11. Lakshminarayana, P. N., \& Deepthi, B. R. (2019). Advent of Artificial Intelligence and its Impact on Top Leading Commercial Banks in India - Case Study. International Journal of Trend in Scientific Research and Development (IJTSRD), Volume - 3 | Issue - 4 | May-Jun, p 614 - 616.

12. Low, C., Chen, Y., \& Wu, M. (2011). Understanding the determinants of cloud computing adoption. Industrial Management \& Data Systems, Vol. 111 No. 7, pp. 1006-1023.

13. Mangiuc, D. (2017). Accountants and the cloud - Involving the professionals. Accounting and Management Information Systems, Bucharest Vol. 16, Iss. 1, pp: 179-198.

14. Moin, K. I., \& Ahmed, Q. B. (2012). Use of Data Mining in Banking. International Journal of Engineering Research and Applications (IJERA), Vol. 2, Issue 2, Mar-Apr, pp.738-742.

15. Moro, S., Cortez , P., \& Paulo, R. (2015). Business Intelligence in Banking. Expert Systems with Applications: Vol. 42(3), pp. 1314-1324.

16. Nanath, K., \& Pillai, R. (2013). A Model for Cost-Benefit Analysis of Cloud Computing. Journal of International Technology and Information Management, San Bernadino Vol. 22, Iss. 3, pp: 95-II.

17. Padhy, R. P., Patra, M. R., \& Satapathy, S. C. (2011). Cloud Computing: Security Issues and Research Challenges. IRACST - International Journal of Computer Science and Information Technology \& Security (IJCSITS), Vol. 1, No. 2, December, pp. 136 - 146.

18. Prasad, M., Naik, R. L., \& Bapuji, V. (2013). Cloud Computing : Research Issues and Implications. Institute of Advanced Engineering and Sciencew w w . i a e sjInternational Journal of Cloud Computing and Services Science (IJ-CLOSER), ISSN: 2089-3337, Vol.2, No.2, April, pp. 134 140.

19. Russell, S., \& Norvig, P. (2003). Artificial Intelligence-A Modern Approach. Dorling Kindersley (India) Pvt. Ltd. pp 16-25, 2nd ed.

20. Sabharwal, M. (2014). The use of Artificial Intelligence (AI) based technological applications by Indian Banks. International Journal of Artificial Intelligence and Agent Technology, 2. 1-5.

21. Shee, H., Shah, J. M., Fairfield, L., \& Pujawan, N. (2018). The impact of cloud-enabled process integration on supply chain performance and firm sustainability: the moderating role of top management. Supply Chain Management, Bradford Vol. 23, Iss. 6, pp. 500-517.

22. Sinha, D. M. (2017). Artificial intelligence -banks in india. International Journal in Management and Social Science, Vol.05 Issue-07, July, 474 - 478.

23. Vatsa, M., Chaudhary, S. and Dharwal, M., 2021. Mechanics of environmental concern of car buyers in India. Materials Today: Proceedings, 37, pp.2247-2251.

24. Sophia, M. (2018, January 17). Banks Are Taking Note As Fintech Spikes Customers' Interest. Forbes, pp. https://www.forbesmiddleeast.com/banks-are-taking-note-as-fintech-spikes-customers-interest.

25. Kaura, P., Dharwal, M., Kaur, H. and Kaur, P., 2019. Impact of Corporate Governance on Financial Performance of Information Technology Companies. International Journal of Recent Technology and Engineering, 8(3), pp.7460-7464.

26. Srivastava, P., \& Khan, R. (2018). A Review Paper on Cloud Computing. International Journals of Advanced Research in Computer Science and Software Engineering , ISSN: 2277-128X (Volume-8, Issue-6) pp. 17-20. 